\title{
The formation of methemoglobin by the action of nitrite on bovine blood
}

\author{
N. Vertregt
}

Centre for Agrobiological Research (CABO), Wageningen, the Netherlands

Accepted: 15 June 1977

Key words: methemoglobin, nitrite, blood, cattle

\section{Summary}

Reactions of nitrite with hemoglobin in cattle blood under conditions of oxygen saturation and under conditions of oxygen exclusion are described.

Each mole of oxyhemoglobin monomer reacts with $1 \mathrm{~mol}$ of nitrite resulting in the formation of $1 \mathrm{~mol}$ of methemoglobin and $1 \mathrm{~mol}$ of nitrate.

Each mole of hemoglobin monomer reacts with 1 mol of nitrite producing a relatively stable $\mathrm{HbNO}$ compound. $\mathrm{HbNO}$ decomposes during the normal methemoglobin analysis, leading to the formation of $2 \mathrm{~mol}$ of methemoglobin and $1 \mathrm{~mol}$ of nitrate.

Under in vivo conditions both reactions occur simultaneously. As a consequence a simple stoichiometric equation of the reaction of nitrite on blood cannot be given.

In addition the results obtained with the widely used Evelyn and Malloy method of methemoglobin analysis deviate from the methemoglobin content as measured in whole blood. An estimation of the extent of the analytical differences is given.

\section{Introduction}

The methemoglobin ( $\mathrm{Hi}$ ) forming action of nitrite on blood is often summarized as a reaction between oxyhemoglobin $\left(\mathrm{HbO}_{2}\right)$ and nitrite:

$$
2 \mathrm{HbO}_{2}+\mathrm{NO}_{2}^{-}+\mathrm{H}_{2} \mathrm{O} \rightarrow 2 \mathrm{HiOH}+\mathrm{NO}_{3}-+\mathrm{O}_{2}
$$

(Greenberg et al., 1944; Jung \& Remmer, 1949; Jung et al., 1967; Betke et al., 1956). In the present communication $\mathrm{Hb}$ and $\mathrm{Hi}$ refer to the monomer molecule.

Because methemoglobin is unable to carry oxygen, heavy nitrite loads producing high methemoglobin contents may cause death of the animal as a result of anoxia.

The reaction mechanism is certainly more complicated than given by Eq. 1 . First, the literature data differ considerably as to the proportion of utilized nitrite to the methemoglobin formed. The recorded molar ratios appear to vary from 2 to 0.5 (Bodansky, 1951; Rodkey, 1976). Secondly, no conformity is found concerning the amount of oxygen. The records of the molar ratio of $\mathrm{O}_{2}$ evolved to methemoglobin varied from 0.5 to zero. (Kiese, 1974; Marshall \& Marshall, 1945; Meier, 
1925; Greenberg, 1944; Bodansky, 1951; Rodkey, 1976).

The following formulation has the virtue of simplicity. Only a single heme nucleus is involved in the reaction with a nitrite ion; however, a separate $\mathrm{H}$-donator has to cooperate in the reaction.

$$
\mathrm{HbO}_{2}+\mathrm{NO}_{2}-+\mathrm{AH} \rightarrow \mathrm{HiOH}+\mathrm{NO}_{3}^{-}+\mathrm{A} .
$$

In the living cow only about half of the venous blood pigment is present as oxyhemoglobin. Because nitrite can react with the remaining hemoglobin as well, it is relevant also to consider the reaction of nitrite with hemoglobin in the absence of oxygen. This reaction is often represented as:

$$
2 \mathrm{Hb}+\mathrm{NO}_{2}^{-}+\mathrm{H}^{+} \rightarrow \mathrm{HiOH}+\mathrm{HbNO}
$$

(Brooks, 1937; Meier, 1925; Jung \& Remmer, 1949; van Assendelft \& Zijlstra, 1965). However, the absorption spectra published by van Assendelft \& Zijlstra bear no evidence of the formation of $\mathrm{HbNO}$, because the form of their spectrum for $\mathrm{HbNO}$ is exactly intermediate between the $\mathrm{Hb}$ and $\mathrm{Hi}$ spectra. Therefore, the applicability of Eq. 3 in the interpretation of experimental data remains questionable.

Formation of nitrite from ingested nitrate in the rumen and the consequent formation of methemoglobin in the blood of the living cow has recently been studied in relation to nitrate content and composition of the feed (Kemp et al., 1977). For a more detailed interpretation of the data more knowledge was required about the action of nitrite in the blood than the contradictory data from the literature could supply. This more specific information on the action of nitrite on hemoglobin has been the primary object of the present study.

Most of the work on the subject has been carried out with an excess of nitrite over methemoglobin added to washed erythrocytes. Our purpose was to investigate the action of added amounts of nitrite smaller than the hemoglobin content of samples of whole blood, and to measure the proportion of nitrite, nitrate, hemoglobin and methemoglobin at successive stages of the reaction.

\section{Methods}

\section{Determination of total hemoglobin}

The hemoglobin and methemoglobin in a $0.02 \mathrm{ml}$ sample of heparinized blood were converted to methemoglobincyanide by the addition of $5.00 \mathrm{ml}$ of a solution of $0.75 \mathrm{mmol}$ potassium cyanide, $0.6 \mathrm{mmol}$ potassium ferricyanide, $1 \mathrm{mmol}$ potassium dihydrogenphosphate buffer at $\mathrm{pH} 6.8$ per litre. The extinction at $540 \mathrm{~nm}$ is 11,000 $\mathrm{cm}^{2} \mathrm{mmol}^{-1}$ (van Kampen \& Zijlstra, 1961).

\section{Determination of methemoglobin}

In hemolysed blood (Evelyn and Malloy, 1938). Within 5 minutes after sampling, $0.300 \mathrm{ml}$ of heparinized blood was mixed with $20 \mathrm{ml}$ of a $\mathrm{pH} 6.9$ buffer solution 
containing $4.04 \mathrm{~g} \mathrm{KH}_{2} \mathrm{PO}_{4}$ and $6.5 \mathrm{~g} \mathrm{NA}_{2} \mathrm{HPO}_{4} \cdot 2 \mathrm{H}_{2} \mathrm{O}$ per litre, and with two drops of a $10 \%$ saponin solution. After 2 minutes the extinction at $630 \mathrm{~nm}$ was determined in one half of the clear solution. To the remaining $10 \mathrm{ml}$ of the blood solution were added two drops of a $10 \% \mathrm{KCN}$ solution, and the extinction of the formed cyanomethemoglobin was determined at $630 \mathrm{~nm}$. The methemoglobin content was calculated from the difference between the two extinctions. The coefficient of the extinction difference proved to be $3250 \mathrm{~cm}^{2} \mathrm{mmol}^{-1}$.

In whole blood. With a tubing pump heparinized whole blood was passed through a $0.125 \mathrm{~mm}$ flow cuvette placed near the exit slit of the sample compartment of a recording spectrophotometer, and during the flow the spectrum was recorded. Since the light passed through 10 layers of erythrocytes, the spectrum of the optically heterogeneous whole blood was of a quality equal to that of hemolysed blood. Because the experimental conditions did not permit a conversion of the methemoglobin to cyanomethemoglobin, methemoglobin had to be calculated from the extinction difference $\mathrm{E}_{630}-\left(\mathrm{E}_{610}+\mathrm{E}_{650}\right) / 2$.

A straigt calibration graph was obtained from the extinction values taken at these wavelengths from figure 1 and the corresponding methemoglobin contents determined according to the Evelyn and Malloy method.

\section{Determination of nitrite in blood plasma}

An automatic analyser was used with the following modules: sampler, proportioning pump, $38{ }^{\circ} \mathrm{C}$ heating bath, dialyser, colorimeter with $15 \mathrm{~mm}$ flow-cell and $630 \mathrm{~nm}$ interference filter and recorder.

A sample of plasma was taken up into the analyser followed by twice its volume of a $0.4 \mathrm{~N} \mathrm{NaOH}$ solution. The diluted sample passed a $40 \mathrm{~cm}$ dialyser with a $0.2 \mathrm{~N}$ $\mathrm{NaOH}$ solution flowing along the other side of the membrane. Water and reagents were successively added to the dialysate so that final concentrations were produced of $21 \mathrm{~g}$ phosphoric acid, $1.12 \mathrm{~g}$ sulphanilamide, $0.056 \mathrm{~g}$ naphtylethylene diamine and $0.050-0.75 \mathrm{mg}$ of nitrite per liter of the measuring solution. The original plasma sample was eventually diluted 70 times during its passage through the analyser. After each series of 6 samples a standard solution of $1.0 \mathrm{mmol}$ nitrite per litre was taken for calibration. The extinction is about $30000 \mathrm{~cm}^{2} \mathrm{mmol}^{-1}$.

\section{Determination of nitrate in blood plasma}

A similar method as for the nitrite determination was used for nitrate. The dialysate was brought up to a final concentration of $180 \mathrm{mg}$ of hydrazine sulphate and $10 \mathrm{mg}$ of copper sulphate per litre to reduce the nitrate to nitrite during a 3-minute passage through a heating coil at $38^{\circ} \mathrm{C}$. Then reagents were added for the nitrite determination. This method gives the sum of nitrite and nitrate in the sample and the nitrate content after subtracting the nitrite content determined separately. As about $10 \%$ of the nitrite is reduced by the hydrazin, calibration solutions of nitrite and nitrate had to be used for the nitrate determination. 


\section{Experiments}

Identity of the spectra of methemoglobin in blood after addition of nitrite or ferricyanide respectively

For venous whole blood, containing about equal amounts of oxyhemoglobin and hemoglobin, it might be expected that added nitrite will react according to both Eq. 2 and 3. If this were true, the formation of $\mathrm{HbNO}$ should be indicated by spectral differences between nitrite and ferricyanide treated blood.

To each of a number of $25-\mathrm{ml}$ portions of heparinized intact blood containing $7.70 \mathrm{mmol}$ of hemoglobin per litre were added $0.5-\mathrm{ml}$ portions of solutions containing measured amounts of either sodium nitrite or potassium ferricyanide to produce final concentrations in the blood of $0.294,0.735,1.47,2.94,7.35$ and $14.7 \mathrm{mmol}$ of $\mathrm{NO}_{2}-$ or $\mathrm{Fe}(\mathrm{CN})_{6}{ }^{2-}$ litre $^{-1}$. The samples were kept under air and occasionally shaken to prevent sedimentation.

The spectra were recorded at $0.25,1.7,6.7$ and 25 hours after addition of the reagents, in the hemolysed solutions prepared according to the Evelyn and Malloy method for methemoglobin analysis. A selection of the spectra covering the range of $0-100 \%$ methemoglobin is given in Fig. 1.

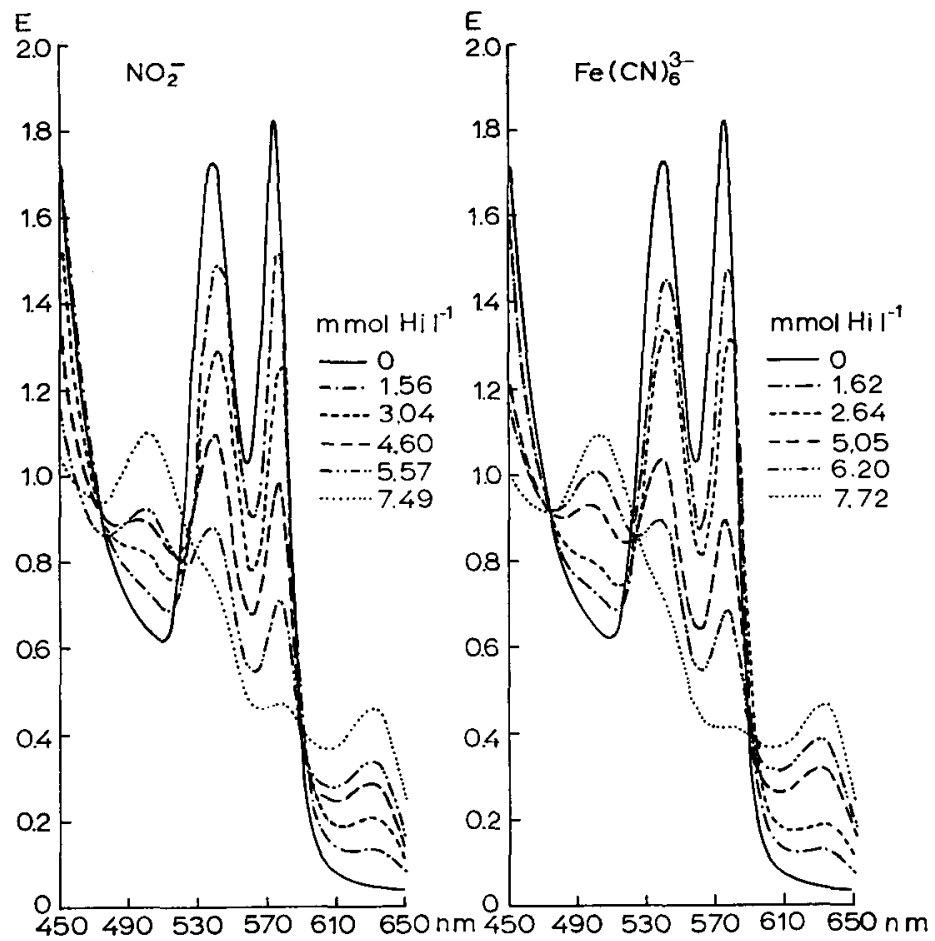

Fig. 1. Absorption spectra in diluted buffer solution of hemoglobin with different contents of methemoglobin following addition of nitrite or ferricyanide to bovine blood. 

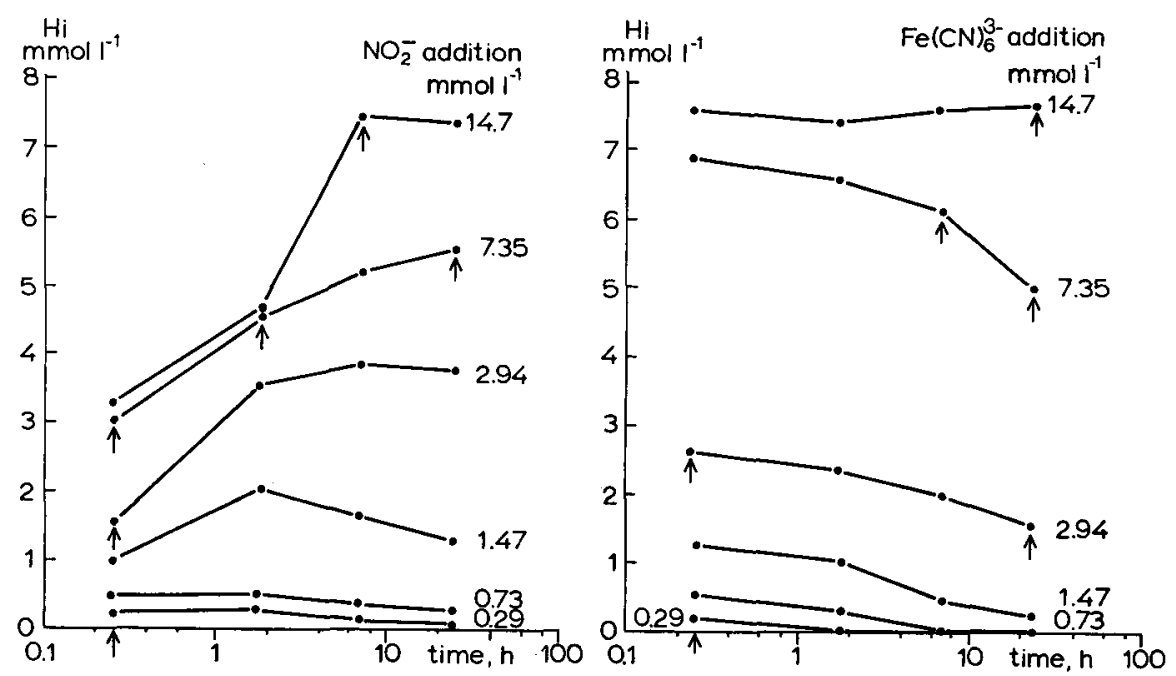

Fig. 2. Methemoglobin formation in bovine blood after addition of different amounts of nitrite or ferricyanide. Added quantities of reagents are indicated in the figure. Samples from which the spectra are represented in Fig. 1 are indicated by arrows.

For both reagents the spectra were essentially similar without any indication of $\mathrm{HbNO}$ or HiNO formation in the nitrite series. Both with nitrite and ferricyanide the ultimate stage was that of a $100 \%$ methemoglobin spectrum, in which the extinction difference at $630 \mathrm{~nm}$ with the corresponding hemoglobincyanide spectrum was 0.460 . From this the extinction coefficient of methemoglobin has been calculated as $3250 \mathrm{~cm}^{2} \mathrm{mmol}^{-1}$.

The time course of the methemoglobin formation under the various conditions is given in Fig. 2. The maximum molar ratio of methemoglobin formed to ferricyanide was 1.0, that of the maximum methemoglobin formed to nitrite was 1.5 , as can be read from the methemoglobin concentrations formed after addition of $0.73,1.47$ and $7.35 \mathrm{mmol} \mathrm{Fe}(\mathrm{CN})_{6}{ }^{3-}$ per litre and 1.57 and $2.94 \mathrm{mmol} \mathrm{NO}_{2}-$ per litre, respectively. At other levels of addition either the reagent or hemoglobin was in short supply. Like in the results of Greenberg (1944), with nitrite a ratio of 2.0 was not attained, not even upon graphical extrapolation of the results, but it was also greater than 1.0. Therefore, the reaction between hemoglobin and nitrite cannot be described by Eq. 2 and 3 .

Stoichiometry of the reaction of nitrite with hemoglobin, methemoglobin determination in hemolysed blood

To $90 \mathrm{ml}$ of freshly sampled heparinized bovine blood kept at $37^{\circ} \mathrm{C}, 10 \mathrm{ml}$ of an isotonic buffer solution of $\mathrm{pH} 6.9$ containing $40 \mathrm{mmol} \mathrm{K \textrm {KH } _ { 2 }} \mathrm{PO}_{4}, 50 \mathrm{mmol} \mathrm{Na} \mathrm{NPO}_{4}$ and $31.1 \mathrm{mmol} \mathrm{NaNO}_{2}$ per litre were added. Methemoglobin concentrations in the blood and nitrite and nitrate concentrations in the blood plasma were determined periodically. The concentrations of nitrate and nitrite in the plasma were recal- 
culated on whole blood basis by taking the solvent volume of the blood into account. This solvent volume was calculated from nitrate concentrations as determined in plasma and in whole blood. Nitrite had to be determined in the plasma, because it reacts immediately with hemoglobin in whole and hemolysed whole blood. The plasma concentration of nitrite is rather constant.

The results of one of the experiments are represented in Fig. 3. After a reaction period of 6 hours all the added nitrite was recovered as nitrate. Before, the sum of the concentrations of nitrate and nitrite was smaller than the initial $3.11 \mathrm{mmol}$ nitrite per litre. Since the analytical data for the first few samplings indicated a high diffusion rate of nitrate and nitrite through the erythrocyte membrane in both directions, unequal distribution between erythrocytes and plasma could not explain the deficit. Possibly some $\mathrm{HbNO}$ is temporarily formed, although this is not indicated by the spectra of Fig. 1 . Since the blood was hemolysed in the methemoglobin determination the nitrite available at the earlier sampling times reacted with hemoglobin to form methemoglobin. It will be clear from Fig. 3 that a considerable difference between the methemoglobin and nitrate course will remain after correction for such a nitrite hemoglobin reaction. It shows that the results of this experiment do not correspond with Eq. 1 and 2.

In the following experiments two variables had to be controlled: the degree of oxygenation of the hemoglobin and the interference of nitrite in the methemoglobin determination.

Stoichiometry of the reaction of nitrite with oxyhemoglobin, determination of methemoglobin in whole blood

A $225-\mathrm{ml}$ sample of heparinized bovine blood containing $5.38 \mathrm{mmol}$ of hemoglobin per litre was saturated with pure oxygen at $37{ }^{\circ} \mathrm{C}$ in a closed flask. A $25-\mathrm{ml}$ subsample was taken for initial analysis. To the remaining $200 \mathrm{ml}, 1 \mathrm{ml}$ of a solution containing $26.8 \mathrm{mg} \mathrm{Na} \mathrm{HPO}_{4} \cdot 2 \mathrm{H}_{2} \mathrm{O}, 14.5 \mathrm{mg}$ citric acid and $55.3 \mathrm{mg} \mathrm{KNO}$ was added, resulting in an initial nitrite content of the blood of $3.17 \mathrm{mmol} \mathrm{NO}_{2}^{--}$litre $^{-1}$.

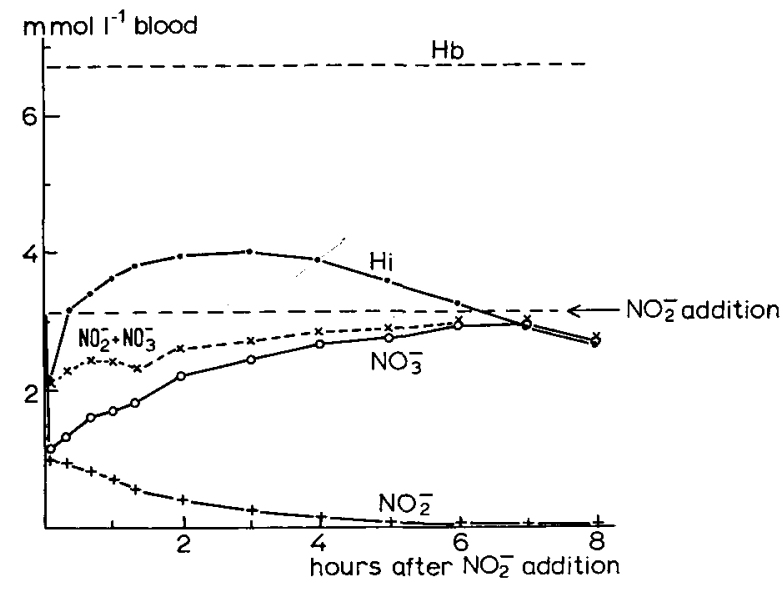

248
Fig. 3. Course lines of reactions after addition of nitrite to whole blood. Levels of hemoglobin content and added nitrite are indicated by dashed lines. 


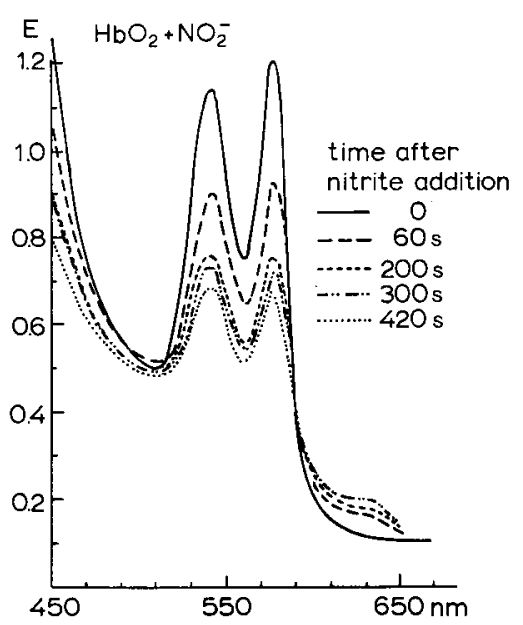

Fig. 4. Absorption spectra of oxygenated whole blood with increasing content of methemoglobin due to progressive reaction with nitrite, directly measured in a $0.125 \mathrm{~mm}$ flow cell.

The mixture was kept under oxygen and swirled continuously. At successive time intervals a fresh sample of blood was passed through the flow cell of the spectrophotometer and subsequently analysed for nitrate and nitrite. The successive spectra are shown in Fig. 4. Seven hours after the addition of nitrite a blood sample was taken and analysed for hemoglobin after hemolysis. In this hemolysed sample the spectra were recorded after several time intervals, 5 and 30 minutes (Fig. 5).

At the end of the 7-hour reaction period only $2 \%$ of the blood in the flask was hemolysed. At that time most of the nitrite had reacted with the oxyhemoglobin as is shown by the evaluated results given in Fig. 6 .

The results of venous (Fig. 3) and of oxygen-saturated whole blood differed markedly. In the oxygenated blood (Fig. 6) not all the nitrite was converted to nitrate and never more methemoglobin was formed than nitrate was formed or

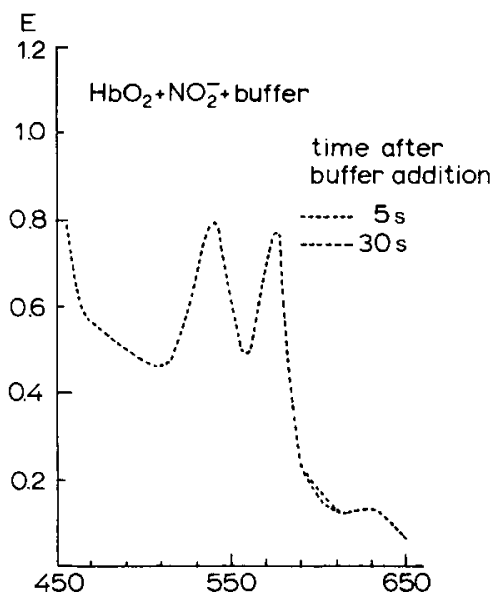

Fig. 5. Spectrum of the $420 \mathrm{~s}$ sample of Fig. 4, diluted from 0.30 to $20 \mathrm{ml}$ with buffer solution, measured in a $10.0 \mathrm{~mm}$ cuvette $5-30$ minutes after hemolysis, respectively. The two spectra coincide. 


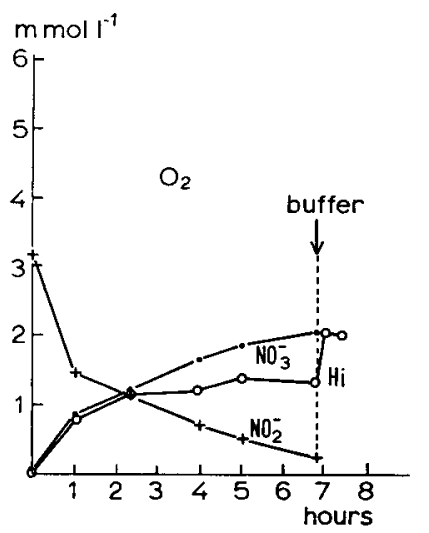

Fig. 6. Course lines of methemoglobin and nitrate formation and nitrite consumption after addition of nitrite to oxygenated blood. Methemoglobin data taken from Fig. 4 and 5. Time of buffer addition is indicated by vertical dashed line.

nitrite was added, whereas in the non-oxygenated venous blood (Fig. 3) methemoglobin was formed in considerable excess during the first few hours. During the first 3 hours in oxygenated blood the reaction between nitrite and oxyhemoglobin would correspond with Eq. 2. But subsequently the formation of methemoglobin in oxygenated whole blood was retarded relative to the increase in the nitrate content in the blood. This discrepancy may have originated from some change in the properties

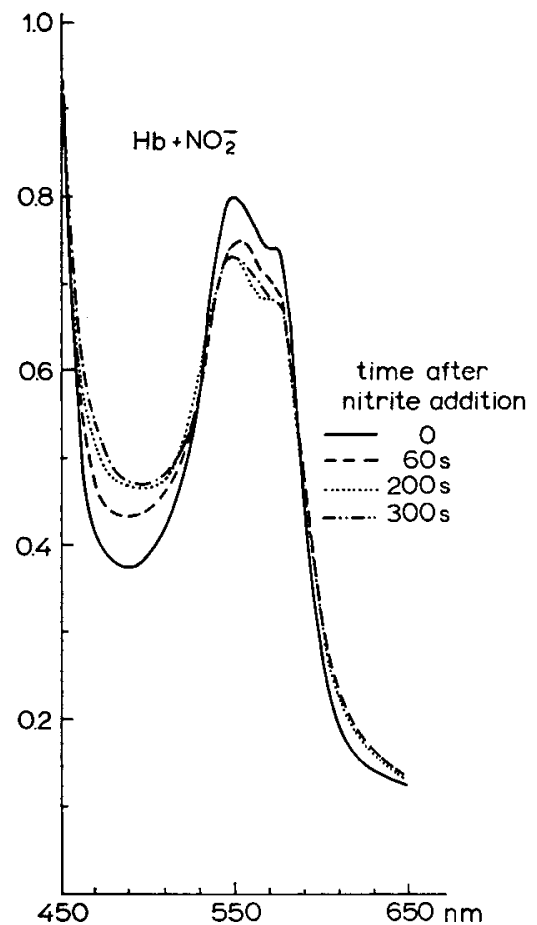

Fig. 7. Similar to Fig. 4, absorption spectra of oxygen-free whole blood after addition of nitrite. 
of the erythrocytes with duration of the reaction period, although this could not be inferred from differences in the spectra of Fig. 4 and 5. However, the effect is too small to be of much importance for the conclusion that nitrate and methemoglobin have been formed in equal concentrations.

Stoichiometry of the reaction of nitrite with hemoglobin, determination of methemoglobin in whole blood

A similar experiment as described in the previous section was conducted under $\mathrm{N}_{2}$ with bovine blood made oxygen-free by alternating evacuation and admission of nitrogen. The treated blood contained $6.01 \mathrm{mmol}$ hemoglobin and $3.71 \mathrm{mmol}$ nitrite per litre. At the end of the 5-hour reaction period $6 \%$ of the blood was hemolysed. Then a sample of the blood was diluted with the oxygen-containing buffer solution and the methemoglobin measured after $0,10,30$ and 120 minutes.

The successive spectra measured during the reaction of nitrite on the whole blood are given in Fig. 7, the spectra of the hemolysed samples are given in Fig. 8, the evaluated analytical results in Fig. 9.

In oxygen-free blood no methemoglobin and only a small amount of nitrite was formed in the 5-hour period, although most of the nitrite reacted. In this reaction period the troughs at $500 \mathrm{~nm}$ in the spectra of Fig. 7 shallow to some extent, which is not very characteristic, but commonly attributed to the formation of NO-hemoglobin (Jung \& Remmer, 1949). With the data obtained so far, nitrite being con-

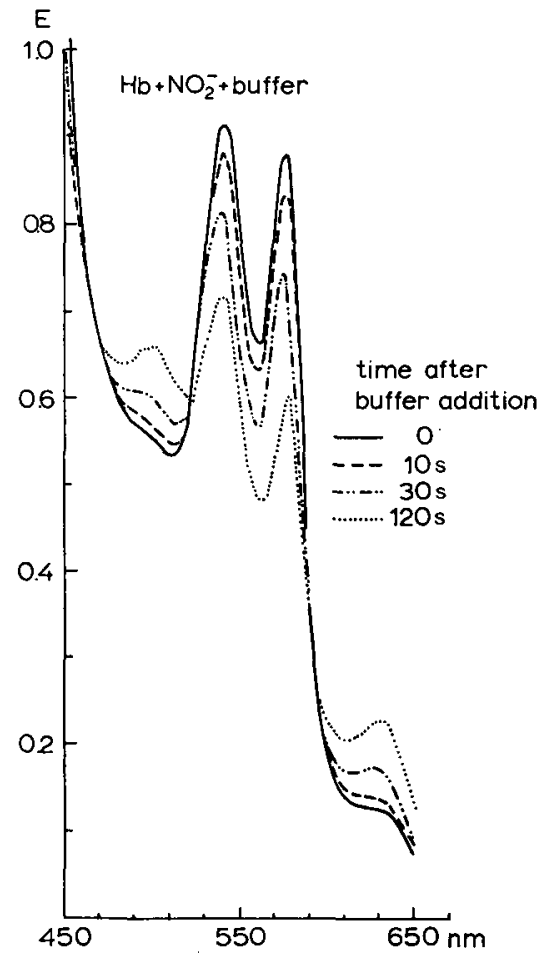

Neth. J. agric. Sci. 25 (1977)
Fig. 8. Spectra of the $300 \mathrm{~s}$ sample of Fig. 7, diluted from 0.3 to $20 \mathrm{ml}$ and measured in a $10.0 \mathrm{~mm}$ cuvet on different times after dilution. 


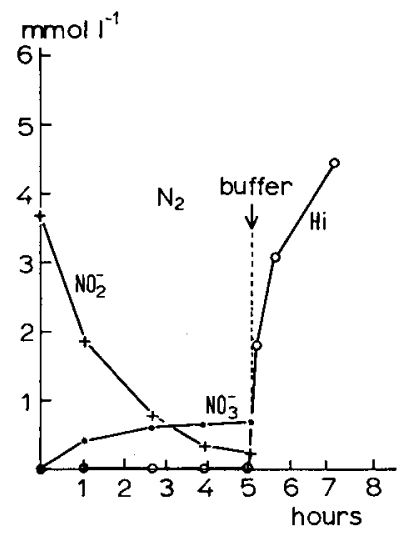

Fig. 9. Course lines of methemoglobin and nitrate formation and nitrite consumption after addition of nitrite to oxygenfree blood. Methemoglobin data taken from Fig. 7 and 8. Time of dilution with oxygen-containing buffer solution is indicated by the arrow.

sumed and no methemoglobin being formed, the reaction between nitrite and hemoglobin without oxygen can be described by the equation:

$$
\mathrm{Hb}+\mathrm{NO}_{2}^{-}+2 \mathrm{H}^{+} \rightarrow \mathrm{HbNO}^{+}+\mathrm{H}_{2} \mathrm{O} \text { (Jung et al., 1967). }
$$

After the 5-hour reaction period, when the samples had been diluted with the oxygen-containing buffer, the spectrum changed within a short period of time, exhibiting a progressive substantial methemoglobin production. The reaction sequence is not clear. Eq. 4 is formulated to account for the observed disappearance of nitrite and the absence of methemoglobin. The presence of $\mathrm{HbNO}^{+}$is not proven, however, an intermediate for the subsequent formaticn of methemoglobin has to be present in the blood. The origin of the relative low amount of nitrate cannot be explained by the proposed equation.

After hemolysis and the unavoidable addition of oxygen the hypothetical $\mathrm{HbNO}^{+}$ probably breaks down to methemoglobin and nitrogen oxide

$$
\mathrm{HbNO}^{+}+\mathrm{OH}^{-} \rightarrow \mathrm{HiOH}+\mathrm{NO}
$$

The nitrogen oxide is converted to a 1:1 mixture of nitrate and nitrite and the resulting nitrite reacts with hemoglobin to form another molecule of methemoglobin (Jung et al., 1967).

The summarized equation of the reaction of nitrite with hemoglobin and the subsequent decomposition of $\mathrm{HbNO}$ in the buffer solution is:

$$
2 \mathrm{Hb}+\mathrm{NO}_{2}-+\mathrm{H}_{2} \mathrm{O}+\mathrm{O}_{2} \rightarrow 2 \mathrm{HiOH}+\mathrm{NO}_{3}-
$$

It was not possible to analyse for nitrate within the necessary short time intervals in the diluted, hemolysed solutions.

\section{Discussion}

It is to be expected that bovine blocd after in vivo introduction of nitrite will contain methemoglobin, nitrate and possibly NO-hemoglobin. In the Evelyn \& Malloy 
(1937) analytical procedure an additional amount of methemoglobin is formed by the following reactions:

- the reaction between nitrite and hemoglobin after hemolysis of the sample;

- the conversion of the supposed $\mathrm{HbNO}$ to $2 \mathrm{Hi}$ during the analytical procedure according to Eq. 4 and 6 . The relative contribution of these reactions to the result of the methemoglobin determination will be discussed below.

The highest nitrite content found in the blood of cows in a series of nitrate feeding experiments was $0.15 \mathrm{mmol}$ nitrite per litre of blood at a level of $9 \mathrm{mmol}$ of nitrite per litre of rumen fluid and of $5 \mathrm{mmol}$ of methemoglobin per litre blood. At lower rumen nitrite or blood methemoglobin contents the blood nitrite content was correspondingly lower. Compared with intact blood, this low nitrite content of the blood will give not more than $5 \%$ higher methemoglobin values in hemolysed blood.

If the nitrite entering venous blood in vivo would react in proportion with the equal amounts of hemoglobin and oxyhemoglobin, it would follow from the present experiments that the methemoglobin content determined according to Evelyn and Malloy in hemolysed blood will be three times higher than measured in whole blood, since in the whole blood the resulting $\mathrm{Hi}$ : $\mathrm{HbNO}$ ratio will be $1: 1$, whereas during hemolysis one $\mathrm{HbNO}$ will react to form two $\mathrm{Hi}$. In practice the difference between the results obtained with the two methods of methemoglobin determination were far less. The methemoglobin determined immediately after sampling in whole blood samples of cows receiving a nitrate containing ration proved to be $30 \%$ lower than the content determined according to the Evelyn and Malloy procedure, in a hemolysed aliquot of the sample.

Obviously, nitrite reacts preferentially with oxyhemoglobin or under in vivo conditions reaction sequence 5 predominates in the reaction between nitrite and hemoglobin. A similar conclusion results from comparison of Fig. 3 with the Fig. 6 and 9 . Physiologically the deviations between the analytical results in whole and hemolysed blood are still less important, since neither $\mathrm{HbNO}$ nor methemoglobin transport oxygen. In addition, it is probable that eventually all the $\mathrm{HbNO}$ will be converted in vivo to methemoglobin, just as the actual nitrite content can be considered as a potential methemoglobin content. Therefore the values of methemoglobin which are undeniably too high when analysed by the Evelyn and Malloy method, may be quite acceptable for the physiological work on nitrite toxicity.

Since other reactions proceed concurrently in whole blood no exact stoichiometry equation for the reaction of nitrite with hemoglobin in the living animal can be given.

In addition, the normally occurring enzymatic reduction of the methemoglobin to hemoglobin antagonizes the net yield of methemoglobin.

\section{References}

Assendelft, O. W. van \& W. G. Zijlstra, 1965. The formation of haemiglobin using nitrites. Clin. chim. Acta 11: 571-577.

Betke, K., I. Greinacher \& O. Tietze, 1956. Oxydation menschlicher und tierischer Oxyhämoglobine durch Natriumnitrit. Arch. exp. Path. Pharmakol. 229: 220-232. 
Bodansky, O., 1951. Methemoglobinemia and methemoglobin producing compounds. Pharmacol. Rev. 3: 144-197.

Brooks, J., 1937. The action of nitrite on haemoglobin in the absence of oxygen. Proc. Royal Soc. London, Series B 123: 368-382.

Evelyn, K. A. \& H. T. Malloy, 1938. Microdetermination of oxyhemoglobin, methemoglobin and sulfhemoglobin in a single sample of blood. J. biol. Chem. 126: 655.

Greenberg, A., D. Lester \& W. Haggard, 1944. The reaction of hemoglobin with nitrite. J. biol. Chem. 151: 665-673.

Jänig, G. R. \& F. Jung, 1970. Über die Reaktion zwischen Natriumnitrit und Hämoglobin. Acta biol. med. german. 25: 355-358.

Jung, F., H. Rein, O. Ristau \& E. Kupfer, 1967. Nitrosohämoglobinaemie bei der Nitritvergiftung. Acta biol. med. german. 19: 1003-1009.

Jung, F. \& H. Remmer, 1949. Uber die Umsetzung zwischen Nitrit und Hämoglobin. Arch. exp. Path. Pharmakol. 206: 459-473.

Kampen, E. J. van \& W. G. Zijlstra, 1961. Standardization of hemoglobinometry. Clin. chim. Acta 6: 538-544.

Kemp, A., J. H. Geurink, R. T. Haalstra \& A. Malestein, 1977. Nitrate poisoning in cattle. 2. Changes in nitrite in rumen fluid and methemoglobin formation in blood after high nitrate intake. Neth. J. agric. Sci. 25: 51-62.

Kiese, M., 1974. Methemoglobinemia; a comprehensive treatise. CRC press Inc., Cleveland.

Meier, R., 1925. 39 Studiën über Methämoglobinbildung. Arch. exp. Path. Pharmakol. 110: 241-264.

Marshall, W. \& Ch. R. Marshall, 1945. The action of nitrites on blood. J. biol. Chem. 158: 187-208.

Rodkey, F. L., 1976. A mechanism for the conversion of oxyhemoglobin to methemoglobin by nitrite. Clin. Chem. 22: 1986-1990. 